\title{
Additive manufacturing of PGE standards with a silica matrix
}

\author{
CORLiss K. SiO ${ }^{1}$, TASHI PARSONS-DAvis ${ }^{1}$, Elaine LeE ${ }^{1}$, \\ JOSH WIMPENNY ${ }^{1}$, ANDREW J. PASCALL ${ }^{1}$, JOSHUA D. \\ KUNTZ ${ }^{1}$, JOHN J. GOODELL ${ }^{1}$, KEVIN E. ROBERTS ${ }^{1}$, \\ BRYAN B. BANDONG ${ }^{1}$, NEIL. R. BENNETT ${ }^{2}$ \\ ${ }^{1}$ Lawrence Livermore National Laboratory, $\mathrm{SiO}_{2} @ 1$ llnl.gov \\ ${ }^{2}$ University of California, Davis
}

Silicate standards for the platinum group elements (PGE) have been identified as an outstanding need for the microanalytical community. Such standards are difficult to synthesize due to the tendency of PGE to form metallic nuggets. Although several experimental designs have been developed to eliminate the formation of these inclusions [13], the resulting samples are too small for widespread distribution. Here, we describe a method to fabricate standards that are nugget-free and large in size/quantity.

Stöber particles approximately $800 \mathrm{~nm}$ in diameter were synthesized in a solution containing ethanol, ammonia hydroxide, water, tetraethyl orthosilicate (TEOS), and precious metals dissolved in $10 \% \mathrm{HCl}$, with the aim to produce $27 \mathrm{~g}$ of silica doped with $1 \mathrm{ppm}$ of precious metals [4]. After rinsing and suspending in ethanol, the particles were consolidated using electrophoretic deposition (EPD). Two samples, each $\sim 20 \times 20 \times 4 \mathrm{~mm}$ in size, were fabricated using the same starting materials. The consolidated samples were calcined and sintered to obtain densified products suitable for use as microanalytical standards. When heated in oxidizing conditions, the PGEs were either partially or quantitatively lost. As a result, thermal processing was performed in a reducing environment.

The sintered samples were characterized by solution and laser ablation ICPMS. The final products contain 0.5-1 ppm of Ru, Rh, Pd, Os, and Ir, but $2.6 \mathrm{ppm}$ of Pt, suggesting Pt contamination from furnace components. Concentration profiles are observed for Pd in the outermost $1 \mathrm{~mm}$ and for Pt in the outermost $80 \mu \mathrm{m}$. Heterogeneity is at the 2-6\% RSD levels for $\mathrm{Ru}, \mathrm{Rh}$, Os, Ir, throughout and $\mathrm{Pd}$ and $\mathrm{Pt}$ in the sample interior. With the exception of Pt, the two samples have identical compositions. These samples represent the most homogeneous PGE silicate standards containing the full suite of PGE. The outlined method has the potential to produce reference materials that are tunable with regard to their major, minor, and trace element compositions, and in sufficient quantities for widespread distribution.

[1] Brenan JM, et al. (2009) Nat Geosci, 2(11), 798-801.

[2] Medard E, et al. (2015) Geochim Cosmochim Acta, 162, 183-201

[3] Bennett NR, et al. (2014) Geochim Cosmochim Acta, 133, 422-442.

[4] Sio CK, et al. (2020) Rapid Commun Mass Spectrom, 34, e8627. 